\title{
A história que se repete
}

\author{
Werner Paul Ott \\ Médico sanitarista e Membro Honorário da Academia Sul-Rio-Grandense de Medicina. \\ E-mail: ott.voy@gmail.com
}

DOI: http://dx.doi.org/I0.21674/2448-0479.63.164-166

Desde a antiguidade, são conhecidos dois micróbios que são primos-irmãos. Um é o Mycobacterium tuberculosis, o outro o Mycobacterium leprae. Ambos são bacilos transmitidos por via aérea pela tosse, espirros, mas geralmente caem logo no chão. Assim, as gotículas não permanecem muito tempo no ar, mas ambos podem provocar doença crônica no homem, cujo nome o próprio sobrenome, ou epíteto específico, indica. No primeiro, a doença é "para dentro", nos pulmões, no segundo é "para fora", na pele. O primeiro tem mais 'glamour' sendo, inclusive, motivo para poemas, e ensaios de cunho romântico dos mais variados, escritos por portadores desta doença. Exemplos na literatura brasileira são: Nelson Rodrigues, Casimiro de Abreu, Castro Alves, Cruz e Souza e Manuel Bandeira. Este último compôs o poema' abaixo de um lirismo realista e amargo:

\section{Pneumotórax}

Febre, hemoptise, dispnéia e suores noturnos.

A vida inteira que podia ter sido e que não foi.

Tosse, tosse, tosse.

Mandou chamar o médico:

- Diga trinta e três.

- Trinta e três... trinta e três... trinta e três...

- Respire.

- O senhor tem uma escavação no pulmão esquerdo e o pulmão direito infiltrado.

- Então doutor, não é possível tentar o pneumotórax?

- Não.

A única coisa a fazer é tocar um tango argentino.

Do segundo, descoberto antes do primo-irmão, pelo cientista norueguês Gerhard Hansen em 1874, os pacientes não tiveram a mesma fase de lirismo. Nunca se ouviu falar em verso ou prosa de um período romântico da doença. O descobrimento do seu primo-irmão foi oito anos depois, em I882, por Robert Koch e logo foi eternizado pelo nome de "bacilo de Koch". Ao cientista norueguês a história fez justiça tardiamente, somente em 1974, quando o nome lepra foi substituído por Hanseníase. Mas o nome de lepra já tinha feito seus estragos. A lepra e o leproso ficaram na boca do povo, por anos e anos. As palavras significavam segregação, isolamento compulsório, afastamento da sociedade, que se apavorava por qualquer lesão de pele por medo de ser contagiado pelo bacilo.

\footnotetext{
I Poema publicado em 1930, no livro Libertinagem.
} 
Por isso, em 1940, foi construído em Porto Alegre o último leprosário no Brasil e tão logo ficou pronto já recebia pacientes, que segundo relatos, até eram buscados em qualquer município do Estado por carros da Polícia. Estas pessoas eram arrancadas do seio de seus familiares para serem internadas e voltar à casa às vezes ou, então, nunca mais. O nosso Hospital Colônia para Leprosos ficava bem longe da sociedade "ameaçada" em Itapuã a 60 km do centro da Capital. Os médicos da Secretaria da Saúde que se deslocavam até o Leprosário de duas a três vezes por semana até direito a meia-diária tinham pela distância percorrida. Este Hospital Colônia, com uma área de mais de 1.000 hectares, era uma cidade dentro da cidade. Além das casas para moradia, tinha praças, escolas, igrejas onde até se realizavam cerimônias de casamento entre os segregados e uma prefeitura com prefeito escolhido entre os próprios doentes. Não havia ociosidade nesta "cidade", pois havia as lavouras e outras opções para atividades manuais para quem podia e queria trabalhar. Havia tudo, menos liberdade de ir e vir para visitar familiares ou amigos. A máxima era ficar isolado, não ter contato com a sociedade. Por isso, o Leprosário contava com uma zona limpa para visitantes e funcionários e outra, digamos suja, exclusiva dos "residentes". Tudo era controlado. Para falar com um visitante, o familiar tinha de pedir a permissão da administração do Hospital. A conversa se dava, em sala separada, devidamente desinfetada, com máscara dos dois lados e com um vidro interposto com, no mínimo, um metro de distância. Esta regra também valia para o atendimento médico.

Até agora falei dos estragos provocados pelo $\mathrm{M}$. leprae e pouco, quase nada, sobre seu primo-irmão, o $\mathrm{M}$. tuberculosis. Este na verdade conheci há mais de 50 anos do Pavilhão Pereira Fo., hospital anexo da Santa Casa de Porto Alegre para tuberculosos crônicos com possibilidade cirúrgica. Era médico Residente (RI) da Faculdade de Medicina da UFRGS e os danos que esse bacilo pode causar eu soube através dos doentes internados e das estatísticas, mas não por quaisquer manifestações em mim até hoje (“tok, tok, tok..."). Não que ele tenha me poupado do contágio, mas, ao que parece, por um acordo tácito unilateral, que apenas um poderia atacar. Pelo jeito, não fui tão eficiente quanto eu esperava e necessitava ser, a julgar pelo número de vítimas atuais.

A história do M. tuberculosis não é muito diferente, talvez um pouco mais branda do que a do primo-irmão. O nome já faz a diferença. Leproso, segundo o dicionário Aurélio, significa, também, repulsivo, repugnante. Tísico, o cognome do tuberculoso, comum antes do advento dos tuberculostáticos, no início dos anos 1950, não chegava a incomodar ninguém. Pelo contrário, o expressivo número de tísicos fazia o gáudio dos médicos do ramo, os Tisiologistas. Era o Pneumotórax de que falava Manuel Bandeira. Ironia à parte, os médicos tisiologistas em qualquer época fizeram o possível para seus pacientes com os recursos disponíveis na ocasião. Nesta oportunidade, não seria justo falar somente da dedicação dos tisiologistas, muitas vezes na retaguarda, sem falar dos «anjos de branco», enfermeiras, geralmente religiosas, trabalhando na frente da batalha expostas diuturnamente as terríveis façanhas dos dois primos-irmãos.

A tuberculose é invisível aos olhos, a não ser nos casos consumptivos, e por isso ela é até ignorada, equivocadamente. Sem dúvida, ainda há preconceito, mas não rechaço na sociedade. Há discriminação no trabalho, e o tabu das pessoas de falar ou de declarar a sua doença, mas não o isolamento compulsório que, segundo me consta, nunca houve. Existiram e ainda existem os hospitais específicos para tuberculosos, os Sanatórios. Nome comum para internar os pacientes para, conforme as recomendações das autoridades sanitárias, recuperar a sua saúde, ou seja, curar-se pelo repouso, regimes higieno-dietéticos e de ar puro "das montanhas". Nada mal para os ricos. Para os menos afortunados, havia os Sanatórios na planície, hospitais padrão para todo o Brasil. O Sanatório Partenon na Avenida Bento Gonçalves de Porto Alegre é um exemplo.

O segundo Sanatório, o Hospital Parque Belém, na época da sua construção, fins da década de 1940, ficava longe do Centro de Porto Alegre e em cima do Morro da Cruz. Assim, do ponto de vista topográfico, atendia os recomendações das autoridades, mas não podia competir com Campos do Jordão, localizada em meio à Mata Atlântica no Estado de São Paulo. Esta cidade na Serra da Mantiqueira, com montanhas acima de $2.000 \mathrm{~m}$, era conhecida por acolher nos hospitais os pacientes tuberculosos e seus familiares e acabou enriquecida com isso. Na Europa, onde este conceito surgiu, foi na Suíça com suas montanhas deslumbrantes e a cidade hoje famosa Davos, local onde a elite europeia com tuberculose se hospedava. Foi neste cenário que se desenrolou o famoso romance "Der Zauberberg" (A Montanha Mágica) de Thomas Mann².

Havia e há, na verdade, certos cuidados individuais dos funcionários da saúde com o bacilo e a doença, pois a tuberculose no Rio Grande do Sul, ao contrário da Hanseníase quase em extinção, se encontra em

\footnotetext{
${ }^{2}$ Obra original publicada em alemão, em 1924.
} 
plena florescência. Até os anos 1970-80, o atendimento médico e de enfermagem era feito com a mesa com vidro separando o paciente a uma distância de no mínimo um metro e meio. Depois este distanciamento foi eliminado por uma questão de humanizar o atendimento.

A comprovação científica de que o tratamento ambulatorial com uso de tuberculostáticos, estreptomicina e isoniazida, era tão eficaz quanto o hospitalar e que o isolamento dos pacientes para proteger os seus familiares do contágio durante os meses iniciais do tratamento (i.e. dois a três meses) era desnecessário. Baseado nisso, a Organização Mundial de Saúde (OMS) recomendou a desativação dos Sanatórios por várias razões. Uma delas era econômica. Assim, estava chegando o fim da era hospitalar.

De fato, o uso correto de várias drogas específicas em um sistema ambulatorial organizado tornava ociosos os milhares de leitos hospitalares neste Brasil afora, custeados por nós contribuintes. As fontes de contágio, os pacientes bacilíferos, deixam de infectar depois de algumas semanas. Assim, os pacientes fora do leito hospitalar passam a travar a luta contra o bacilo em pé. Não em pé de igualdade, pois até agora, os bacilos levam vantagem, infelizmente.

Os poucos leitos para os tuberculosos graves, geralmente por reconhecimento tardio da doença por parte do paciente ou do médico ou ainda do uso inadequado dos medicamentos, fazem pender novamente a balança para o lado dos bacilos. Pelo jeito, eles se tornaram resistente aos tuberculostáticos usados em saúde pública no Brasil e no mundo. Por sorte, existem ainda poucos casos da chamada multirresistência dos bacilos aos medicamentos em nosso meio. Caso este cenário mude, poderá voltar tudo novamente. Os médicos e todos os funcionários do nosocômio fazendo uso obrigatório de máscara e todos os cuidados de não se infectar, porque as chances de se curarem são pequenas.

Fazendo um paralelo, escrevo esse Ensaio no isolamento total e absoluto em um sítio distante cerca de $50 \mathrm{~km}$ de Porto Alegre, onde recebemos ninguém, a mercadoria do cotidiano é encomendada por telefone, o pagamento é feito "on-line" e os produtos recebidos ficam de quarentena. Na rua, vejo as poucas pessoas que circulam passando um metro e meio distantes uma das outras, de máscaras para evitar o contágio via aérea, o que também confunde a minha memória. "Será que esta que acabou de passar era a vizinha da esquina, que não via há meses, ou será que a confundi com a fulana?". Ninguém se abraça para cumprimentar o amigo ou vizinho. O máximo do cumprimento dos íntimos agora é o encontro de dois cotovelos.

Hoje o vilão é outro, completamente diferente, o coronavírus. Partícula minúscula como os primos-irmãos, mas infinitamente menor do que um bacilo, mas de potencial infectante muito maior, que ninguém sabe, ao certo, o quanto. Sem medicação comprovadamente eficaz, sem vacina que sempre foi o nosso meio de prevenção e salvação individual e coletiva. Só na linha de frente, os médicos, o pessoal de enfermagem e outros profissionais abnegados de máscara e trajes de proteção nas UTls, batalhando contra o inimigo com grande desgaste físico, psíquico e emocional e, ainda mais, com risco iminente de se infectar. Neste momento, me passou pela cabeça: "a história se repete". 